\title{
Effects of parental mental illness on children's physical health: systematic review and meta-analysis
}

Matthias Pierce, Holly F. Hope, Adekeye Kolade, Judith Gellatly, Cemre Su Osam, Reena Perchard, Kyriaki Kosidou, Christina Dalman, Vera Morgan, Patricia Di Prinzio and Kathryn M. Abel

\section{Background}

Children of parents with mental disorder face multiple challenges.

\section{Aims \\ To summarise evidence about parental mental disorder and child physical health.}

\section{Method}

We searched seven databases for cohort or case-control studies quantifying associations between parental mental disorders (substance use, psychotic, mood, anxiety, obsessive-compulsive, post-traumatic stress and eating) and offspring physical health. Studies were excluded if: they reported perinatal outcomes only ( $<28$ days) or outcomes after age 18; they measured outcome prior to exposure; or the sample was drawn from diseased children. A meta-analysis was conducted. The protocol was registered on the PROSPERO database (CRD42017072620).

\section{Results}

Searches revealed 15945 non-duplicated studies. Forty-one studies met our inclusion criteria: ten investigated accidents/ injuries; eight asthma; three other atopic diseases; ten overweight/obesity; ten studied other illnesses (eight from low-and middle-income countries (LMICS)). Half of the studies investigated maternal perinatal mental health, 17\% investigated paternal mental disorder and 87\% examined maternal depression. Meta-analysis revealed significantly higher rates of injuries $(\mathrm{OR}=1.15$, 95\% Cl 1.04-1.26), asthma $(\mathrm{OR}=1.26$, 95\% Cl 1.121.41 ) and outcomes recorded in LMICS (malnutrition: $\mathrm{OR}=2.55$, 95\% Cl 1.74-3.73; diarrhoea: $\mathrm{OR}=2.16,95 \% \mathrm{Cl} 1.65-2.84$ ). Evidence was inconclusive for obesity and other atopic disorders.

\section{Conclusions}

Children of parents with mental disorder have health disadvantages; however, the evidence base is limited to risks for offspring following postnatal depression in mothers and there is little focus on fathers in the literature. Understanding the physical health risks of these vulnerable children is vital to improving lives. Future work should focus on discovering mechanisms linking physical and mental health across generations.

\section{Declaration of interest}

None.

\section{Keywords}

Epidemiology; childhood experience; depressive disorders; perinatal psychiatry; low- and middle-income countries.

\section{Copyright and usage}

(c) The Authors 2019.
Only recently has improving the lives of the $20 \%$ of children estimated to have a parent with a mental disorder ${ }^{1-3}$ become a public health priority. ${ }^{4-6}$ Thus, despite these children being likely to experience multiple deprivations and challenges, notably little is known about them or their health needs. Most of the information available about these children relates to their higher risk of developing psychiatric $^{7}$ and neurodevelopmental problems. ${ }^{8-10}$ Prior research has shown that children of parents with mental disorder have a considerably increased risk of congenital anomalies, ${ }^{11}$ of having been born with obstetric complications, including premature birth and low birthweight, ${ }^{12}$ of being stillborn and of premature death (the last persists into adulthood). ${ }^{13,14}$ However, little attention has been paid to a link between parental mental disorder and poorer offspring physical health, defined here as diseases such as asthma or diabetes affecting somatic rather than mental health. This is important not least because poor physical health has a detrimental effect on a child's development, with chronic ill health affecting social functioning ${ }^{15}$ and academic progress. ${ }^{16,17}$ Also, health disparities in childhood often persist into adulthood, leading to lower life expectancy. ${ }^{18}$ Moreover, such a readily identifiable highrisk group could be a suitable target for early interventions.

This systematic review examined whether having a parent with a mental illness increases the risk of physical illness throughout childhood. Prior reviews have focused on maternal depression or anxiety and specific child health outcomes of obesity ${ }^{19-21}$ and asthma. $^{22-24}$ Most of these included self-reported outcomes, cross-sectional designs and studies in which the childhood illness precedes exposure to the parental illness. Our review and metaanalysis included a broad range of parental mental disorders, specified a priori, and any clinically diagnosed child physical health outcome. We limited the scope of the review by using strict definitions of exposure and outcome and by pre-specifying the type of study design. This enabled us to summarise the literature on physical health of children whose parents have mental illness, focusing on studies of higher quality and with clearly defined measures.

\section{Method}

This review was developed according to the Centre for Reviews and Dissemination's 'Guidance for undertaking reviews in health care'. ${ }^{25}$ The protocol was registered on the PROSPERO database (reference: CRD42017072620).

\section{Selection criteria}

Cohort or case-control studies that quantify associations between parental mental disorders and physical health in the offspring were included. This review focused on childhood disease; therefore, we excluded studies reporting outcomes occurring only in the neonatal period (0-28 days) or beyond age 18. Studies were also excluded if: the outcome was measured prior to exposure; the sample size was $<10$; or the cohort sample was drawn from diseased children. If more than one study had overlapping study populations 
and definitions of exposure and outcome, the study with the largest sample was chosen.

We specified a priori parental mental disorders that were of interest: substance use disorders (ICD-10 category: F10-19); schizophrenia, schizotypal and delusional disorders (F20-29); mood disorders (F30-39); anxiety disorders (F40-41); obsessivecompulsive disorders (F42); post-traumatic stress disorder (F43.1); and eating disorders (F50). We included studies where: mental illness was defined by a clinical diagnosis, using ICD or DSM criteria; mental illness was measured using a peer-reviewed instrument; or where the parent received treatment for a mental disorder.

We included studies reporting any physical disease in the offspring, clinically diagnosed and in the World Health Organizations' ICD-10 framework. This excluded psychological or neurobehavioural disorders (i.e. chapter V of ICD-10) and any disorder categorised in ICD-10 chapter VIII: 'Symptoms, signs and abnormal clinical and laboratory findings, not elsewhere classified'.

\section{Search strategy}

We searched the following databases for published papers, reports, conference abstracts and theses: MEDLINE; PsycINFO; PsycARTICLES; Embase; Web of Science; ProQuest ASSIA. We included studies published within the dates 1 January 1970 to the search date (21 September 2017), and did not initially include language restrictions.

We searched using the following general terms: (children) AND (parent) AND (mental illness) AND (physical disease) AND (casecontrol OR cohort study). We included terms for the specific mental illnesses and, for the purposes of conducting the search, an a priori list of common diseases of childhood that was developed by clinical collaborators (R.P. and K.M.A.). We included MESH terms and included variants and synonyms using truncations and wildcards where helpful. The full search strategy can be found in supplementary Appendix A available at https://doi.org/10.1192/bjp.2019.216. Following screening, we sought to identify further studies by hand-searching review papers arising from our searches. We also conducted hand-searches of reference lists of identified papers and we conducted a cited-reference search using Web of Science.

\section{Screening}

Duplicates were removed and then two reviewers (M.P. and A.K.) screened titles and abstracts, initially piloting 250 papers to ensure that consistent features were selected. All studies categorised as 'yes' or 'maybe' for inclusion were extracted for full text screening. A full-text screening tool was piloted by three reviewers (M.P., A.K. and J.G.) using 30 papers and then the same three reviewers divided all full-text papers between them so that each paper was screened twice. Disagreements and ambiguities were resolved in a group discussion, calling on a fourth reviewer (K.M.A.) as necessary. Lack of resources meant that we excluded papers that were not in English.

\section{Data extraction and analysis}

Data extraction was carried out by two reviewers (M.P. and A.K.), extracting data on: outcome type, exposure type; assessment instrument used; timing of exposure and outcome; sample size; study setting; statistical model; variables used in adjustment; and effect size. Study quality was assessed using the National Institutes of Health (NIH) Quality Assessment Tools using checklists developed for cohort and case-control studies. ${ }^{26}$

When studies used multiple adjusted models, we report from the model with the most covariates, unless we judged that any of the extra variables were on the causal pathway between exposure and outcome. When studies presented multiple effect sizes from multiple exposures we report only those exposures considered by the studies' authors to be the most severe and most chronic. All extracted effect sizes are presented in supplementary Appendix B. For meta-analysis, when a study reported multiple outcomes we selected the most frequent and when studies reported the effect of maternal and paternal exposure we selected estimates associated with maternal exposure.

For evidence synthesis, studies were grouped according to outcome type. For each grouping, estimates were converted into odds ratios (where possible) and pooled odds ratios were estimated using random-effects meta-analyses. Between-study heterogeneity was estimated using the $I^{2}$ statistic. Two sensitivity analyses were conducted. First, we determined the robustness of the meta-analyses to removing studies that were ranked poor quality. Second, where appropriate we compared estimates by type of study (case-control versus cohort design). Analyses were done using Stata 14 for Windows using the metan command.

\section{Results}

The database searches yielded 15945 non-duplicate studies (Fig. 1). Of these, 251 were considered for full-text screening and 221 were excluded (94 failed the outcome criteria; 37 failed the exposure criteria; 36 were non-relevant study designs; 12 were reviews; 12 selected a diseased-only cohort; 7 were in a language other than English; 7 did not report sufficient data; 6 were outside the age range; 4 had exposure subsequent to disease; 2 were nested within a larger study; and we were unable to locate the full text for 4). This resulted in 30 studies for inclusion. After additional searches, a further 11 studies were included (5 from other reviews, 5 from reference lists of included papers and 1 from the cited reference search), giving a final total of 41 studies.

\section{Overview of included studies}

The vast majority of included studies (31/41) investigated exposure to parental depression; 7 investigated anxiety, 5 substance misuse and 1 psychotic disorder (Table 1). One study defined exposure as 'psychiatric morbidity', another as 'common mental disorder' and another considered the effect of post-traumatic stress disorder. None investigated the effect of parental eating, bipolar or obsessive-compulsive disorders. All studies examined maternal mental disorder; $17 \%$ (7/41) also examined exposure to paternal mental disorder. Forty-two percent of studies (17/41) measured exposure only during the perinatal period, defined here as from the start of pregnancy to 1 year after the birth. The median age at the last follow-up was 5 years (interquartile range $\mathrm{IQR}=2-7.5$ ) and the median sample size was $1696(\mathrm{IQR}=294-12618)$.

The majority (26) were prospective cohort studies; 8 were retrospective cohort studies and 7 were case-control studies. Thirty-nine percent (16) came from Europe (half of which were from Scandinavia) and 29\% (12) were from North America. Sixty-eight percent (28) were carried out after 2010 and the earliest study was from 1981.

Studies were grouped into the categories according to their outcomes: accidents and injuries $(n=10)$; asthma $(n=8)$; other atopic diseases $(n=3)$; overweight and obesity $(n=10)$. The remaining studies were split between those from a low- and middle-income country (LMIC) setting $(n=8)$ (mainly consisting of studies examining diarrhoea or malnutrition) and those from a high-income country setting $(n=2)$. 


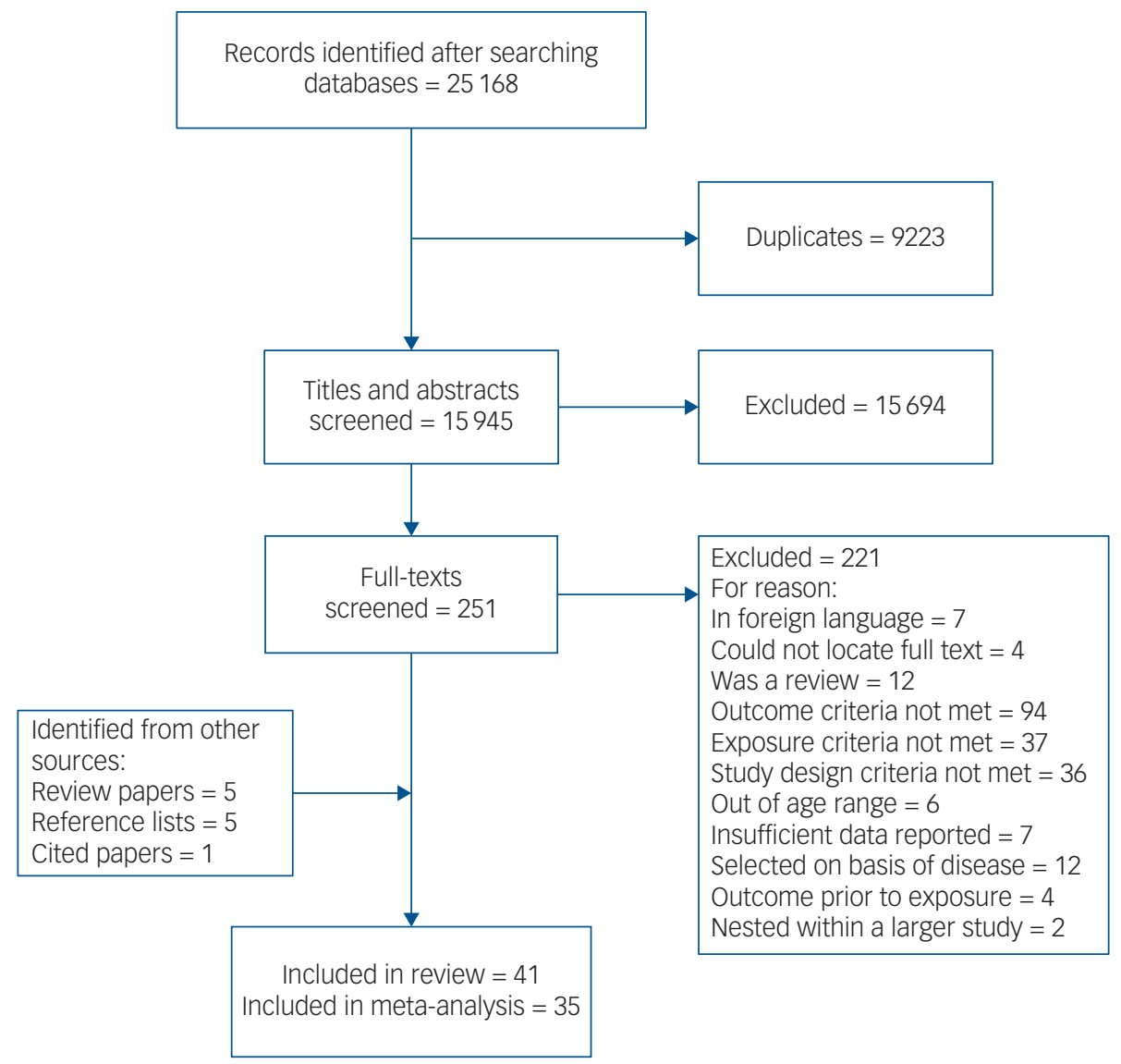

Fig. 1 Flow diagram for studies included in systematic review.

\section{Accidents or injuries (ten studies)}

Of the ten studies that reported accidents and injuries, ${ }^{27-36}$ nine $^{28-36}$ and a combined sample of 314132 children were included in the pooled analysis for accidents and injuries (Fig. 2). This revealed a $15 \%$ increase in the likelihood of a child having an accident or injury if they were exposed to parental mental illness $\left(\mathrm{OR}_{\mathrm{pool}}=\right.$ $1.15,95 \%$ CI $1.04-1.26, I^{2}=76.4 \%$ ).

Five of the six studies that considered the risk of offspring accidents or injuries associated with maternal depression found a positive association $^{27-31}$ and one study, which was the smallest and the only one to examine paternal as well as maternal depression, did not find an effect ${ }^{32}$ (Table 2). Most studies examined outcomes in the first 5 years; however, one study of a birth cohort of 1265 found an effect of maternal depression on traumatic brain injuries up to age $15 .{ }^{28}$

Three studies examined parental substance use disorder and injuries. ${ }^{33-35}$ One reported a doubling in the risk of traumatic brain injury if either parent had misused alcohol ${ }^{33}$ and another small study $(n=125)$ estimated a similar effect of maternal substance misuse, ${ }^{34}$ although the lower confidence interval included a null effect. A large retrospective cohort study from Finland $(n=$ 113813 ) did not find an effect of maternal or paternal substance misuse on risk of injuries in the first 6 years. ${ }^{35}$

One study examined accidents in the first year of life for 199 children with maternal psychotic disorder matched to 787 children without. $^{36}$ They did not find an increased risk of accidents associated with maternal exposure.

\section{Asthma (eight studies)}

From eight studies ${ }^{37-44}$ and a combined sample of 450202 children, we estimated a $19 \%$ increase in the odds of childhood asthma for children exposed to parental mental illness $\left(\mathrm{OR}_{\mathrm{pool}}=1.19,95 \% \mathrm{CI}\right.$ $\left.1.08-1.32, I^{2}=77.0 \%\right)$.

Six of the eight studies found a positive association between maternal depression or anxiety and childhood asthma. ${ }^{37-41}$ The remaining two studies also had effect sizes indicating a positive relationship, albeit with confidence intervals that include a null effect. ${ }^{42,43}$ Three of these studies also reported on exposure to paternal mental disorder ${ }^{39-41}$ but only one detected an effect. ${ }^{40}$ Those that investigated short-term versus chronic depression found a greater effect of the latter. ${ }^{38,44}$ One study that looked at depression exposure during pregnancy versus exposure postnatally did not find a difference. $^{40}$

\section{Other atopic diseases (three studies)}

In the pooled analysis, using three studies ${ }^{45-47}$ and 23471 children, there was inconclusive evidence for an association between parental mental illness and childhood atopy $\left(\mathrm{OR}_{\mathrm{pool}}=1.36,95 \%\right.$ CI $0.91-$ $2.03, I^{2}=92.9 \%$ ).

However, a large cohort study from Taiwan reported a positive effect of maternal depression on risk of infant eczema in the first 6 months of life. ${ }^{45}$ One study reported an association between atopic dermatitis and maternal anxiety, but not maternal depression ${ }^{46}$ and another reported an association with maternal (but not paternal) depression for inhalant (but not food) allergies. ${ }^{47}$

\section{Overweight or obesity (ten studies)}

The pooled analysis for the effect of parental mental illness and being overweight or obese in childhood included seven studies ${ }^{50-54,56-57}$ and 36309 children. To facilitate pooling, overweight was selected in the meta-analysis. The pooled estimate showed borderline 


\begin{tabular}{lr|}
\hline \multicolumn{2}{l}{ Table 1 Descriptive summary of the 41 studies included in the } \\
systematic review \\
\hline Variable \\
Study design \\
Case-control study \\
Cohort study \\
$\quad$ Prospective & $7(17.1)$ \\
$\quad$ Retrospective & $34(82.9)$ \\
Origin of sample & $26(63.4)$ \\
Africa & $8(19.5)$ \\
Australasia & \\
Asia & $4(9.8)$ \\
Europe & $2(4.9)$ \\
North America & $4(9.8)$ \\
South America & $16(39.0)$ \\
Year study published & $12(29.3)$ \\
Before 2000 & $3(7.3)$ \\
2000-2004 & \\
2005-2009 & $2(4.9)$ \\
2010-2014 & $4(9.8)$ \\
After 2015 & $7(17.1)$ \\
Outcome & $15(36.6)$ \\
Accidents/injuries & $13(31.7)$ \\
Asthma & \\
Other atopic diseases & $10(24.4)$ \\
Overweight/obesity & $8(19.5)$ \\
Malnutrition & $3(7.3)$ \\
Diarrhoea & $10(24.4)$ \\
Other & $5(12.2)$ \\
Mental disorder ${ }^{a}$ & $3(7.3)$ \\
Depression & $2(4.9)$ \\
Anxiety & \\
Substance misuse & $31(75.6)$ \\
Other & $7(17.1)$ \\
Parent in whom mental disorder was measured & \\
Mothers & $5(12.2)$ \\
Fathers & $4(9.8)$ \\
a. These categories not mutually exclusive. & \\
& $41(100.0)$ \\
& $7(17.1)$ \\
& \\
\hline
\end{tabular}

evidence to conclude a positive association $\left(\mathrm{OR}_{\mathrm{pool}}=1.16,95 \% \mathrm{CI}\right.$ $\left.0.97-1.39, I^{2}=55.0 \%\right)$. The three studies unsuitable for pooling reported equivocal results. ${ }^{48,49,55}$

Of the nine studies that examined childhood obesity and its association with maternal depression or anxiety, one small cohort study $(n=160)$ estimated a positive association, ${ }^{48}$ seven were equivocal ${ }^{49-55}$ and one reported a negative effect. ${ }^{56}$ Of the three studies that examined duration of maternal depressive disorder, two found an increased risk associated with cumulative exposure to depression, but not of exposure to periodic depression. ${ }^{51,54}$ Two large prospective cohort studies, based in The Netherlands and the USA, ${ }^{52,53}$ indicated an effect of maternal depression on childhood overweight in their unadjusted analyses, but when adjusted for potential confounders (including maternal/paternal body mass index) this effect disappeared.

One Finnish study of 4525 teenagers that examined the association between parental harmful drinking and offspring obesity did not find an effect. ${ }^{57}$

\section{Other studies from low- and middle-income countries (eight studies)}

Five studies from LMICs with a combined sample of 851 children investigated the effect of maternal mental illness on childhood malnutrition. ${ }^{58-62}$ The pooled risk of malnutrition was more than double for exposed compared with unexposed children $\left(\mathrm{OR}_{\mathrm{pool}}=\right.$ $2.55,95 \%$ CI $1.74-3.73, I^{2}=0.0 \%$ ).

Three studies and 13430 children were pooled to investigate the link between perinatal maternal depression and diarrhoea or gastrointestinal infection and, similarly, the odds of diarrhoea doubled for exposed children $\left(\mathrm{OR}_{\text {pool }}=2.16,95 \%\right.$ CI $1.65-2.84$, $\left.I^{2}=52.0 \%\right){ }^{63-65}$

\section{Other studies from high-income countries (two studies)}

One retrospective cohort study of 107587 children in the UK reported an association between maternal perinatal depression and offspring gastrointestinal infection and respiratory tract infections. ${ }^{66}$ Another retrospective cohort study of 2552 children of mothers with alcohol or substance use disorder in Finland found a marginal effect on diseases of the eye, ear and mastoid process. ${ }^{67}$

\section{Study quality}

Overall, 10 studies were graded 'good', 19 studies were 'fair' and 12 studies were graded 'poor' (supplementary Appendix C). Particular methodological problems were the lack of clarity regarding sample selection and the measurements used, and overlapping timing of exposure and outcome. Removing studies that were graded 'poor' (supplementary Appendix D) made little difference to the pooled estimates. Also, for the two meta-analyses that included casecontrol studies, the results were consistent by type of study design (supplementary Appendix E).

\section{Discussion}

\section{Summary of findings}

For the first time, this systematic review summarises current evidence on risk for poor physical health in offspring of parents with mental disorder. Overall, this detailed evidence synthesis paints a picture of relatively poor physical health in the children of parents with mental disorder, with pooled effect estimates revealing an increased risk of injuries, asthma, malnutrition and diarrhoea. However, we highlight striking gaps in the evidence: over threequarters of the studies focused exclusively on maternal depression and, of those, half on postnatal depression; there is little information about children of parents with mental disorders other than depression or anxiety; and few studies investigated the impact of paternal mental disorder.

In total, $63 \%$ of studies (26/41) reported an effect of parental mental disorder on physical health outcomes in the offspring. A further $17 \%$ of studies (7/41) estimated a positive association, albeit with $95 \%$ confidence intervals that include a null effect. Most of the identified studies examined the relationship between exposure to parental mental illness (predominantly maternal postnatal depression) and risk of childhood injuries $(n=10)$, obesity $(n=10)$ or asthma $(n=8)$. Of note, no eligible studies assessed risk of childhood cancers, diabetes, epilepsy or migraine and only one assessed the impact of serious mental disorders such as schizophrenia or bipolar disorder on childhood physical health. Similarly, no studies assessed effects of dual diagnosis, maternal or paternal personality disorder or eating disorders.

\section{Research in context}

We identified evidence of an increased risk of childhood accidents or injuries associated with parental mental illness $\left(\mathrm{OR}_{\text {pool }}=1.15\right.$, $95 \%$ CI $1.04-1.26){ }^{27-35}$ Self-reported data have shown that periods of depression affect a mother's ability to supervise her child. ${ }^{68}$ Substance misuse, particularly alcohol dependence, is associated with violent behaviour, ${ }^{69}$ which may confer additional risk of injury to the child. The one study that examined the effect of psychosis on risk of childhood accidents did not find an effect, although the confidence intervals indicate that it was underpowered to detect 


\begin{tabular}{|c|c|c|c|c|}
\hline Study & Exposure & Outcome & & OR (95\% Cl) \\
\hline $\begin{array}{l}\text { Injuries } \\
\text { Wilson et al (1981)34 } \\
\text { Howard et al }(2003)^{36} \\
\text { Wingvist et al }(2007)^{33} \\
\text { McKinlay et al (2010) } \\
\text { Schwebel et al }(2010)^{32} \\
\text { Myhre et al }(2012)^{29} \\
\text { Orton et al }(2012)^{30} \\
\text { Baker et al }(2017)^{31} \\
\text { Raitasalo et al }(2017)^{35} \\
\text { Subtotal }\end{array}$ & $\begin{array}{l}\text { Substance misuse } \\
\text { Psychosis } \\
\text { Alcohol misuse } \\
\text { Depression } \\
\text { Depression } \\
\text { Distress } \\
\text { Depression } \\
\text { Depression/anxiety } \\
\text { Substance misuse }\end{array}$ & $\begin{array}{l}\text { Accidents } \\
\text { Accidents } \\
\text { Traumatic brain injury } \\
\text { Traumatic brain injury } \\
\text { Injuries } \\
\text { Injuries } \\
\text { Fractures } \\
\text { Fractures } \\
\text { Injuries }\end{array}$ & $\begin{array}{l}\frac{1}{=} \\
\frac{1}{1} \\
\frac{1}{5} \\
\frac{1}{b}\end{array}$ & $\begin{array}{l}1.90(0.80-4.54) \\
0.98(0.55-1.74) \\
1.99(1.19-2.33) \\
1.49(1.00-2.30) \\
1.00(0.98-1.03) \\
1.09(1.03-1.16) \\
1.06(0.93-1.20) \\
1.24(1.06-1.45) \\
1.12(0.84-1.50) \\
1.15(1.04-1.26)\end{array}$ \\
\hline $\begin{array}{l}\text { Asthma } \\
\text { Klinnert et al }(2001)^{42} \\
\text { Kozyrskyj et al }(2008)^{44} \\
\text { Cookson et al }(2009)^{37} \\
\text { Lange et al }(2010)^{39} \\
\text { Giallo et al }(2015)^{38} \\
\text { Kozyrskyj et al }(2017)^{43} \\
\text { Magnus et al }(2017)^{41} \\
\text { Brew et al }(2018)^{40} \\
\text { Subtotal }\end{array}$ & $\begin{array}{l}\text { Depression } \\
\text { Depression/anxiety } \\
\text { Anxiety } \\
\text { Depressive symptoms } \\
\text { Depression } \\
\text { Depression } \\
\text { Depression } \\
\text { Depression/anxiety }\end{array}$ & $\begin{array}{l}\text { Asthma } \\
\text { Asthma } \\
\text { Asthma } \\
\text { Asthma } \\
\text { Asthma } \\
\text { Asthma } \\
\text { Asthma } \\
\text { Asthma }\end{array}$ & $\frac{E}{\frac{E}{E}} \longrightarrow$ & $\begin{array}{l}1.41(0.98-2.03) \\
1.25(1.01-1.37) \\
1.03(0.86-1.23) \\
1.13(1.01-1.27) \\
2.70(1.59-4.59) \\
1.15(0.85-1.56) \\
1.19(1.09-1.30) \\
1.44(1.34-1.56) \\
1.26(1.12-1.41)\end{array}$ \\
\hline $\begin{array}{l}\text { Other atopic disorders } \\
\text { Wang et al }(2016)^{45} \\
\text { Letourneau et al }(2017)^{46} \\
\text { Elbert et al }(2017)^{47} \\
\text { Subtotal }\end{array}$ & $\begin{array}{l}\text { Depression } \\
\text { Depression/anxiety } \\
\text { Depression }\end{array}$ & $\begin{array}{l}\text { Atopic dermatitis } \\
\text { Atopic dermatitis } \\
\text { Inhalant allergy }\end{array}$ & $\frac{1}{\square}$ & $\begin{array}{l}1.42(1.21-1.66) \\
0.93(0.82-1.05) \\
2.07(1.43-2.97) \\
1.36(0.91-2.03)\end{array}$ \\
\hline $\begin{array}{l}\text { Overweight } \\
\text { Ajslev et al }(2010)^{50} \\
\text { Santos et al }(2010)^{51} \\
\text { Wojcicki et al }(2011)^{56} \\
\text { Guxens et al }(2013)^{52} \\
\text { Wang et al }(2013)^{53} \\
\text { Audelo et al }(2016)^{54} \\
\text { Figueiredo et al }(2017)^{57} \\
\text { Subtotal }\end{array}$ & $\begin{array}{l}\text { Distress } \\
\text { Depression } \\
\text { Depression } \\
\text { Depression } \\
\text { Depression } \\
\text { Depression } \\
\text { Alcohol misuse }\end{array}$ & $\begin{array}{l}\text { Overweight } \\
\text { Overweight } \\
\text { Overweight } \\
\text { Overweight } \\
\text { Overweight } \\
\text { Overweight } \\
\text { Overweight }\end{array}$ & $\frac{t}{5}$ & $\begin{array}{l}1.01(0.96-1.07) \\
1.60(1.00-2.60) \\
0.28(0.03-0.92) \\
1.09(0.92-1.30) \\
1.50(0.96-2.33) \\
2.40(1.10-5.60) \\
1.00(0.61-2.02) \\
1.16(0.97-1.39)\end{array}$ \\
\hline $\begin{array}{l}\text { LMIC setting-malnutrition } \\
\text { De Miranda et al (1996) } \\
\text { Anoop et al }(2004)^{59} \\
\text { Adewuya et al }(2008)^{60} \\
\text { Santos et al }(2011)^{61} \\
\text { Ashaba et al }(2015)^{62} \\
\text { Subtotal }\end{array}$ & $\begin{array}{l}\text { Mental disorder } \\
\text { Depression } \\
\text { Depression } \\
\text { Common mental disorder } \\
\text { Depression }\end{array}$ & $\begin{array}{l}\text { Malnutrition } \\
\text { Malnutrition } \\
\text { Malnutrition } \\
\text { Malnutrition } \\
\text { Malnutrition }\end{array}$ & 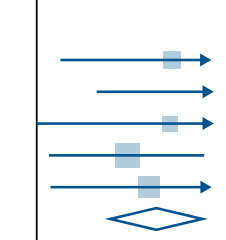 & $\begin{array}{l}2.90(1.20-6.90) \\
7.40(1.60-38.50) \\
2.84(0.98-8.24) \\
2.04(1.10-3.78 \\
2.40(1.11-5.18) \\
2.55(1.74-3.73)\end{array}$ \\
\hline $\begin{array}{l}\text { LMIC setting-diarrhoea } \\
\text { Rahman et al }(2004)^{63} \\
\text { Weobong et al }(2015)^{65} \\
\text { Okronipa et al }(2012)^{64} \\
\text { Subtotal }\end{array}$ & $\begin{array}{l}\text { Depression } \\
\text { Depression } \\
\text { Depression }\end{array}$ & $\begin{array}{l}\text { Diarrhoea } \\
\text { Diarrhoea } \\
\text { Diarrhoea }\end{array}$ & $\stackrel{\square}{\longrightarrow}$ & $\begin{array}{l}2.40(1.70-3.30) \\
1.80(1.45-2.14) \\
2.89(1.71-4.89) \\
2.16(1.65-2.84)\end{array}$ \\
\hline
\end{tabular}

Fig. 2 Forest plot displaying estimates and pooled estimates of the effect of childhood exposure to parental mental illness on childhood disease.

less than a doubling in the rate of accidents. ${ }^{36}$ All but two of these studies on accident and injury followed children in the first 6 years of life and therefore we do not know whether the risk is ameliorated by school entrance.

We highlight evidence to of an increased risk of childhood asthma associated with parental mental illness $\left(\mathrm{OR}_{\mathrm{pool}}=1.26\right.$, 95\% CI 1.12-1.26) and some evidence to suggest an increased risk of other atopic disorders $\left(\mathrm{OR}_{\mathrm{pool}}=1.36,95 \% \mathrm{CI} 0.91-2.03\right)$. The association was observed most strongly in studies in which the exposure was categorised as severe ${ }^{37}$ or chronic. ${ }^{40,45}$ Prior research has reported psychosis and atopic disorders clustering in individuals $^{70,71}$ and families. ${ }^{71}$ The familial link between mental and atopic disorders could arise as a result of shared aetiological factors but also as a result of the effects of adversity. Parental mental disorder increases risks for a range of adversities during childhood, such as poverty ${ }^{72,73}$ and trauma. ${ }^{74}$ Exposure to adversity and stress can alter a child's immune response, ${ }^{75}$ which in turn increases the risk for atopy. ${ }^{76}$ Yet, the link between mental disorders and atopy is likely complex and might include combinations of direct and indirect effects of parental disorder, as well as shared environmental factors (such as smoking).

The evidence for a link between parental mental illness and childhood overweight or obesity is inconclusive. Prior reviews that included cross-sectional studies did report a correlation between maternal depression or anxiety and childhood obesity $;^{19,21}$ another that included only prospective designs found 
Table 2 Summary of analyses from studies included in the systematic review

Study

Accidents

Wilson $1981^{34}$

Howard $2003^{36}$

Phelon $2007^{27}$

Winqvist $2007^{33}$

McKinlay $2010^{28}$

Schwebel $2010^{32}$

Myhre $2012^{29}$

Orton $2012^{30}$

Baker $2017^{31}$

Raitasalo $2017^{35}$

Asthma

Klinnert $2001^{42}$

Kozyrskyj $2008^{44}$

Cookson $2009^{37}$

Lange $2010^{39}$

Giallo $2015^{38}$

Kozyrskyj $2017^{43}$

Magnus $2017^{4}$

Brew $2018^{40}$

Other atopic diseases

Wang $2016^{45}$

Letourneau $2017^{46}$

Elbert $2017^{47}$

Obesity/overweight

De Sousa $2009^{48}$

Prosp. cohort, USA, 8693

Case-control, India, 160

Prosp. cohort, Denmark, 2112

Prosp. cohort, Brazil, 3792

Santos $2010^{5}$

Wojcicki $2011^{56}$

\section{Design, country, $n$}

Retro m

Prosp. cohort, USA, 1106

Prosp. cohort, USA, 584

$$
\text { UK, } 104512
$$$$
\text { (pairs) }
$$

Prosp. cohort, Australia, 4165 Prosp. cohort, Canada, 1696

Retro. cohort, Sweden, 360526

Prosp. cohort, Taiwan, 18024

Prosp. cohort, Canada, 242
Exposure (age measured)

Prosp matched cohort, USA, 125 Substance misuse (8 wks gest. to birth)

Retro. cohort Finland, 12058

Psychosis (2y prior to birth)

Unit increase in depression score (0-6y)

Maternal or paternal alcohol misuse (0-14 y)

Depression (6-13y)

Depression (5-6y)

, Norway, 26087

nested case-control study, Depression (pregnancy to $6 \mathrm{~m}$ )

\section{Types of injuries (0-5 y)}

Prosp. cohort, Netherlands, 5205

Depression (6y)

Long-term mood or anxiety disorder (0-6y)

Anxiety (32 wks pregnancy and $8 \mathrm{wks}$ )

Depression symptoms (0-1 y)

Persistent and high depression symptoms ( $3 \mathrm{~m}$ to $7 \mathrm{y}$ )

Depression (0-18 m)

Major depression (18 wks pregnancy)

Depression or anxiety (continuously through preconception, pregnancy and postnatally)

Depression $(6 \mathrm{~m})$

Depression or anxiety $(3 \mathrm{~m})$

Depression (2nd trimester and $3 \mathrm{y}$ )

Depression (9 m)

Depression score (mean: $9.53 \mathrm{y}$ )

Distress (6 $\mathrm{m})$

Depression $(3,12,24,48 \mathrm{~m})$

Depression (2nd trimester and 4-6 wks)
Injuries (0-6 y)

Asthma (6-8y)

Asthma (7 y)

Asthma (7.5 y)

Asthma (3 y)

Asthma (6-7 y)

Asthma (10 y)

Asthma (7y)

Effect measure: estimate $(95 \% \mathrm{Cl})$

OR: $1.90(0.80-4.54)$

OR: $0.98(0.55-1.74)$

OR: $1.04(1.01-1.08)$

aRR: $1.99(1.19-2.33)$

HR: $1.49(1.0-2.3)$

OR Maternal: 1.00 (0.98-1.03)

Paternal: $1.00(0.97-1.03)$

OR: 1.09 (1.03-1.16)

aOR Poisonings: 1.45 (1.24-1.70)

OR Fractures: 1.06 (0.93-1.20)

aOR Thermal injuries: 1.15 (1.021.32)

alRR Poisonings: 2.30 (1.93-2.75)

Fractures: $1.24(1.06-1.44)$

Burns: 1.53 (1.29-1.81)

Serious injuries: 0.95 (0.60-1.50)

aOR Maternal: 1.12 (0.84-1.50)

Paternal: 1.03 (0.86-1.23)

\section{OR: $1.41(0.98-2.03)$}

aOR: $1.25(1.01-1.37)$

aOR 32 wks: $1.03(0.86-1.23)$

8 wks: $1.12(0.84-1.50)$

aOR: $1.13(1.01-1.27)$

aOR: 2.70 (1.59-4.59)

aOR: $1.15(0.85-1.56)$

aOR Maternal: 1.19 (1.09-1.30)

Paternal: 0.95 (0.81-1.11)

Asthma (5 y)

Atopic dermatitis (3y)

Atopic dermatitis (18 m)

Allergy (9-10 y)

OR Maternal: $1.44(1.34-1.56)$

Paternal: $1.11(1.01-1.21)$

aOR: $1.42(1.21-1.66)$

aOR: $0.93(0.82-1.05)$

aOR Maternal/inhalant: 2.07 (1.43-2.97) Maternal/food: 0.75 (0.29-0.97)

Paternal/inhalant: 1.58 (0.89-2.80)

Paternal/food: 0.87 (0.18-4.14)

Overweight (2 y)

Obesity

Overweight (7 y)

Overweight (0-4 y)

Overweight (6m-2y)
Path coefficient: $0.025, P=0.29$

Weight, mean (s.d.), $\mathrm{kg}$ :

Normal 3.69 (2.95), Obese: 7.75

$(4.31), P=0.29$

aOR: $1.01(0.96-1.07)$

aOR: $1.6(1.0-2.6)$

aOR: 0.28 (0.03-0.92)

(Continued) 


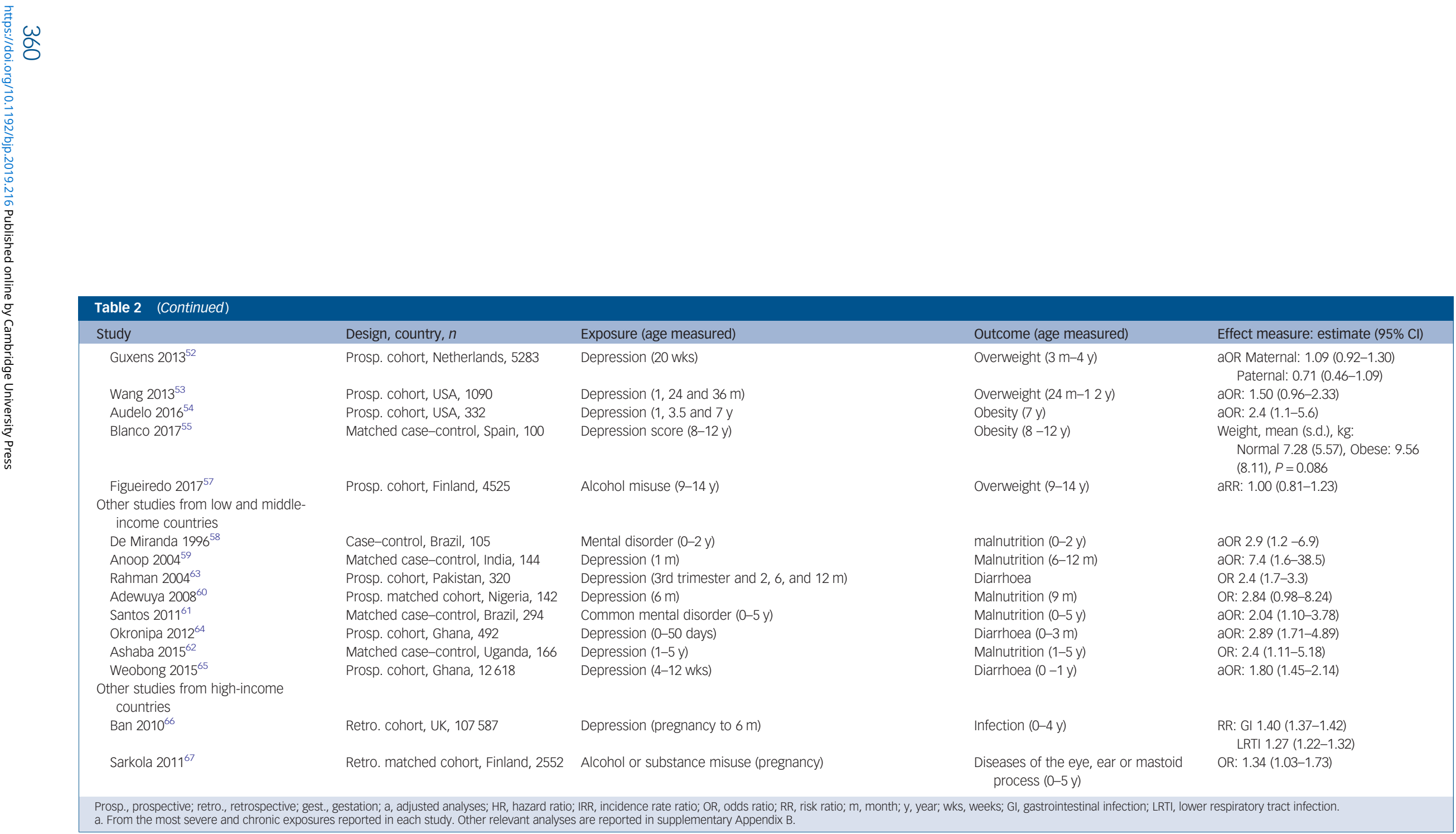

Prosp., prospective; retro., retrospective; gest., gestation; a, adjusted analyses; HR, hazard ratio; IRR, incidence rate ratio; $\mathrm{OR}$, odds ratio; RR, risk ratio; $m$, month; $y$, year; wks, weeks; $G 1$, gastrointestinal infection; LRT, lower respiratory tract infection. 
a link with chronic, but not with episodic (mostly postnatal), maternal depression. ${ }^{20}$ All of the studies we identified that investigated this relationship used prospective cohort or case-control designs, which generally had smaller samples than studies that used registry-based cohorts. Therefore, the lack of definitive findings may be due to lack of power of individual studies.

All the studies from LMICs reported a positive association between maternal depression and offspring malnutrition or diarrhoea. Half of these exclusively examined the effect of postnatal depression in the first year after birth. Recent reviews have reported rates of maternal postnatal depression in LMICs of around 20\%, ${ }^{77}$ considerably higher than the $6.5-12.9 \%$ seen in affluent Western populations. ${ }^{78}$ Evidence also suggests that maternal mental ill health is associated with both poor fetal and child growth. ${ }^{79,80}$ Therefore, maternal mental health has been highlighted as a priority target for screening mothers in these settings. ${ }^{81}$

\section{Strengths and limitations}

The review highlights how children of parents with mental illness have multiple physical health challenges, on top of previously identified mortality ${ }^{13,85}$ and neurodevelopmental risks. ${ }^{7,86}$ Several strengths of our review reinforce the findings. First, although the different outcomes under consideration preclude direct comparison of estimates, there is general consistency in the effect sizes estimated, lending weight to the evidence. Also, we use strict definitions of study design; this means that the estimates are better approximations of effect sizes than if weaker study designs were used: i.e. cross-sectional studies. Therefore, we indicate where potential mechanistic explanations should be explored, so that modifiable factors might be identified to help this vulnerable group. The included studies come from heterogeneous samples, countries, settings, measures and designs. This strengthens the conclusions of the review because, as the results generally show consistency, we can assume that the findings are independent of these factors.

To date, this is the most comprehensive review and meta-analysis of the associations between parental mental illness and offspring physical illness during childhood, however there are a number of limitations. Few studies investigated the effect of both maternal and paternal mental illness and, generally, they noted weaker effects for paternal exposure. ${ }^{36,41,42,53}$ This indicates that maternal condition plays a more important role in the risk of offspring physical ill health, either as a result of intrauterine exposures, or through early childhood experiences or both; it also provides some evidence against a purely genetic cause for these relationships.

All the identified studies come from observational settings and are therefore subject to confounding bias. Most attempted to account for this bias, primarily using regression adjustment. Notably, most of the adjusted analyses were closer to a null effect size. This indicates that, overall, factors that increase the risk of parental mental illness are also likely to increase the risk of poor physical health in offspring (and vice versa). One obvious candidate for a variable of this kind is socioeconomic or multiple deprivation, inextricably linked with parental mental ill health ${ }^{82}$ and poor child physical health. ${ }^{18,83}$

Despite adjustment for confounders, we must be cautious before attributing the causes of poor child physical health to parental mental disorders. First, not all the potential confounders are likely to be identified and measured in data available to researchers. Two of the more recent studies tried to account for residual confounding from familial factors by investigating whether associations still persist using sibling or cousin analysis ${ }^{40,41}$ or when investigating paternal exposure. ${ }^{40}$ Second, some studies may be subject to overadjustment, where analyses adjust for variables on the pathway between the exposure and the outcome. For example, poor fetal growth is associated with both prenatal maternal mental disorder ${ }^{84}$ as well as many health outcomes. Therefore, this might be the mechanism by which prenatal maternal mental disorder influences child health and studies that adjust for this might be underestimating the effect of maternal mental illness on child health. Third, although we excluded studies in which it was clear that the outcome was measured before the exposure occurred, for many studies this was unclear. Therefore, we cannot rule out that at least some portion of the results were because poor child health affects parental mental illness and not vice versa. Fourth, although we actively tried to include unpublished research, all the identified studies were from the published literature. Therefore, it might well be that some positive findings are the result of publication bias.

\section{Implications for future research and policy}

This systematic review shines a stark light on the gaps in our knowledge about the physical health of children whose parents have mental illness, and highlights a need to shift the focus of research towards parental mental disorders other than maternal postnatal depression. Future studies should interrogate the extent to which antenatal, perinatal and postnatal exposures have differential effects on offspring's risk of physical illness. Also, maternal mental disorder may pose more risk to child physical health than paternal disorder but there is a strong need for future studies to include paternal exposure where possible if we are to understand the mechanisms behind these effects in particular outcomes. This chimes well with recent calls for research and policy to place a greater emphasis on the role of fathers in children's lives. ${ }^{87}$

Future research should interrogate the associations highlighted here to explore behavioural, environmental and genetic causes. To do this we highlight a need to develop fresh approaches to understanding the links between child physical health and parental mental health. These include the necessity of accounting for key confounders and to consider the use of alternative design strategies, including negative controls, sibling or quasi-experimental designs. ${ }^{88}$ If future research is to be able to deepen our understanding of when and how these vulnerable children are at risk of preventable illnesses, large high-quality cohorts must be identified. For example, to investigate mechanisms of childhood asthma (still the most common childhood illness) we need to look at effects of different parental illnesses and effects of maternal versus paternal mental disorder. Combining data across such cohorts from different countries may offer such an opportunity.

Finally, from a policy perspective, such approaches can offer the detail needed to plan resource allocation and develop new service provision. Studies describing patterns of healthcare utilisation by these children and parents may be particularly valuable for this.

Matthias Pierce (D), PhD, Research Fellow, Centre for Women's Mental Health, Division of Psychology and Mental Health, Faculty of Biology, Medicine and Health, University of Manchester, UK; Holly F. Hope (D), PhD, Research Associate, Centre for Women's Mental Health, Division of Psychology and Mental Health, Faculty of Biology, Medicine and Health, University of Manchester, UK; Adekeye Kolade, MRes, Research Assistant, Centre for Women's Mental Health, Division of Psychology and Mental Health, Faculty of Biology, Medicine and Health, University of Manchester, UK; Judith Gellatly, PhD, Research Fellow, Centre for Women's Mental Health, Division of Psychology and Mental Health, Faculty of Biology, Medicine and Health, University of Manchester, UK; Cemre Su Osam, MSc, PhD Student, Centre for Women's Mental Health, Division of Psychology and Mental Health, Faculty of Biology, Medicine and Health, University of Manchester, UK; Reena Perchard, MBChB, MRCPCH, Clinical Research Fellow, Division of Developmental Biology \& Medicine, Faculty of Biology, Medicine and Health, University of Manchester, UK; Kyriaki Kosidou, MD, PhD, Senior Consultant, Department of Public Health Sciences, Division Public Health Epidemiology, Karolinska Institutet, Stockholm and Centre for Epidemiology and Community Medicine, Stockholm County Council Sweden; Christina Dalman, MD, PhD, Professor of Psychiatric Epidemiology and Research Group Leader, Department of Public Health Sciences, Division Public Health Epidemiology, Karolinska Institutet, Stockholm; and Centre for Epidemiology and Community Medicine, Stockholm County Council, Sweden; Vera Morgan, MSocSc, PhD, Winthrop Professor and Head, Neuropsychiatric Epidemiology Research Unit, Division of Psychiatry University of Western Australia, Australia; Patricia Di Prinzio BSC, MBiostat, Research Fellow, Neuropsychiatric Epidemiology Research Unit, Division of Psychiatry, 
University of Western Australia, Australia; Kathryn M. Abel, MBBS, FRCP, FRCPsych, PhD, Professor of Psychological Medicine and Director, Centre for Women's Mental Health, Division of Psychology and Mental Health, Faculty of Biology, Medicine and Health, University of Manchester, UK

Correspondence: Matthias Pierce, Centre for Women's Mental Health, Room 3.320, Jean MCFarlane Building, Oxford Road, Manchester M13 9PL, UK. Email: matthias.pierce@ manchester.ac.uk

First received 11 May 2018, final revision 19 Aug 2019, accepted 7 Sep 2019

\section{Funding}

This project has received funding from the European Research Council (ERC) under the European Union's Horizon 2020 research and innovation programme (grant agreement no. GA682741) and the National Institute for Health Research Grant (grant reference 111905).

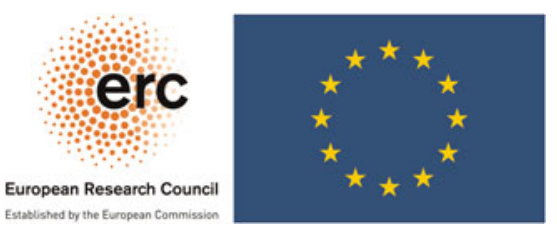

\section{Supplementary material}

Supplementary material is available online at https://doi.org/10.1192/bjp.2019.216.

\section{References}

1 Bassani DG, Padoin C V, Philipp D, Veldhuizen S. Estimating the number of children exposed to parental psychiatric disorders through a national health survey. Child Adolesc Psychiatry Ment Health 2009; 3: 6

2 Maybery DJ, Reupert AE, Patrick K, Goodyear M, Crase L. Prevalence of parental mental illness in Australian families. Psychiatrist 2009; 33: 22-6.

3 Abel KM, Hope H, Swift E, Parisi R, Ashcroft DM, Kosidou K, et al. Prevalence of maternal mental illness among children and adolescents in the UK between 2005 and 2017: a national retrospective cohort analysis. Lancet Public Health 2019; 4: e291-300.

4 Puras D, Kolaitis G, Tsiantis J. Child and adolescent mental health in the enlarged European Union: overview of the CAMHEE project. Int J Ment Health Promot 2010; 12: 3-9.

5 Diggins M, Child T, Parent T. Think Family: A Guide to Parental Mental Health and Child Welfare. SCIE, 2011.

6 Abel KM, Hope H, Faulds A, Pierce M. Promoting resilience in children and adolescents living with parental mental illness (CAPRI): children are key to identifying solutions. Br J Psychiatry 2019: 1-3.

7 Rasic D, Hajek T, Alda M, Uher R. Risk of mental illness in offspring of parents with schizophrenia, bipolar disorder, and major depressive disorder: a metaanalysis of family high-risk studies. Schizophr Bull 2014; 40: 28-38.

8 Fairthorne J, De KN, Leonard $\mathrm{H}$. The relationship between maternal psychiatric disorder, autism spectrum disorder and intellectual disability in the child: a composite picture. J Autism 2015; 2: 2.

9 Shen H, Magnusson C, Rai D, Lundberg M, Lê-Scherban F, Dalman C, et al. Associations of parental depression with child school performance at age 16 years in Sweden. JAMA Psychiatry 2016; 73: 239-46.

10 Berg L, Back K, Vinnerljung B, Hjern A. Parental alcohol-related disorders and school performance in 16-year-olds: a Swedish national cohort study. Addiction 2016: 111: 1795-803.

11 Webb RT, Pickles AR, King-Hele SA, Appleby L, Mortensen PB, Abel KM. Parental mental illness and fatal birth defects in a national birth cohort. Psychol Med 2008; 38: 1495-503.

12 Stein A, Pearson RM, Goodman SH, Rapa E, Rahman A, McCallum M, et al. Effects of perinatal mental disorders on the fetus and child. Lancet 2014; 384 1800-19.

13 Webb R, Abel K, Pickles A, Appleby L. Mortality in offspring of parents with psychotic disorders: a critical review and meta-analysis. Am J Psychiatry 2005: 162: $1045-56$.

14 Webb RT, Sc M, Abel KM, Appleby L, King-Hele SA, Mortensen PB. Mortality risk among offspring of psychiatric inpatients: a population-based follow-up to early adulthood. Am J Psychiatry 2006; 163: 2170-7.

15 Meijer SA, Sinnema G, Bijstra JO, Mellenbergh GJ, Wolters WHG. Social functioning in children with a chronic illness. J Child Psychol Psychiatry 2000; 41 309-17.
16 Thies KM. Identifying the educational implications of chronic illness in school children. J Sch Health 1999; 69: 392-7.

17 Currie J. Healthy, wealthy, and wise: socioeconomic status, poor health in childhood and human capital development. J Econ Lit 2008; 47: 87-122.

18 Rough $\mathrm{E}$, Goldblatt $\mathrm{P}$, Marmot $\mathrm{M}$, Nathanson $\mathrm{V}$. Inequalities in child health. In Growing Up in the UK: Ensuring a Health Future for Our Children (eds A Mansfield, G Foyle, V Nathanson): 37-56. BMA Board of Science, 2013.

19 Milgrom J, Skouteris $\mathrm{H}$, Worotniuk T, Henwood A, Bruce L. The association between ante- and postnatal depressive symptoms and obesity in both mother and child: a systematic review of the literature. Womens Health Issues 2012; 22: e319-28.

20 Lampard AM, Franckle RL, Davison KK. Maternal depression and childhood obesity: a systematic review. Prev Med 2014; 59: 60-7.

21 Benton PM, Skouteris H, Hayden M. Does maternal psychopathology increase the risk of pre-schooler obesity? A systematic review. Appetite 2015; 87: 259-82.

22 Easter G, Sharpe L, Hunt CJ. Systematic review and meta-analysis of anxious and depressive symptoms in caregivers of children with asthma. J Pediatr Psychol 2015; 40: 623-32.

23 van de Loo KFE, van Gelder MMHJ, Roukema J, Roeleveld N, Merkus PJFM, Verhaak CM. Prenatal maternal psychological stress and childhood asthma and wheezing: a meta-analysis. Eur Respir J 2016; 47: 133-46.

24 Andersson NW, Hansen MV, Larsen AD, Hougaard KS, Kolstad HA, Schlünssen V. Prenatal maternal stress and atopic diseases in the child: a systematic review of observational human studies. Allergy 2016; 71 : $15-26$.

25 Tacconelli E. Systematic reviews: CRD's guidance for undertaking reviews in health care. Lancet Infect Dis 2010; 10: 226.

26 National Heart, Lung and Blood Institute. Study Quality Assessment Tools. National Institutes of Health (https://www.nhlbi.nih.gov/health-topics/studyquality-assessment-tools). Accessed 14 February 2018.

27 Phelan K, Khoury J, Atherton $\mathrm{H}$, Kahn RS. Maternal depression, child behavior, and injury. Inj Prev 2007; 13: 403-8.

28 McKinlay A, Kyonka EGE, Grace RC, Horwood $\sqcup$, Fergusson DM MacFarlane MR. An investigation of the pre-injury risk factors associated with children who experience traumatic brain injury. Inj Prev 2010; 16: 31-5.

29 Myhre MC, Thoresen S, Grogaard JB, Dyb G. Familial factors and child characteristics as predictors of injuries in toddlers: a prospective cohort study. BMJ Open 2012; 2: e000740.

30 Orton E, Kendrick D, West J, Tata LJ. Independent risk factors for injury in preschool children: three population-based nested case-control studies using routine primary care data. PLOS One 2012; 7(4): e35193.

31 Baker R, Kendrick D, Tata $\sqcup$, Orton E. Association between maternal depression and anxiety episodes and rates of childhood injuries: a cohort study from England. Inj Prev 2017; 6: 396-402.

32 Schwebel DC, Brezausek CM. How do mothers and fathers influence pediatric injury risk in middle childhood? J Pediatr Psychol 2010; 35: 806-13.

33 Winqvist $\mathrm{S}$, Jokelainen J, Luukinen $\mathrm{H}$, Hillbom M. Parental alcohol misuse is a powerful predictor for the risk of traumatic brain injury in childhood. Brain Inj 2007: 21: 1079-85.

34 Wilson GS, Desmond MM, Wait RB. Follow-up of methadone-treated and untreated narcotic-dependent women and their infants: health, developmental, and social implications. J Pediatr 1981; 98: 716-22.

35 Raitasalo K, Holmila M. Parental substance abuse and risks to children's safety, health and psychological development. Drugs Educ Prev Policy 2017; 24: 17-22.

36 Howard LM, Goss C, Leese M, Thornicroft G. Medical outcome of pregnancy in women with psychotic disorders and their infants in the first year after birth. $B r$ J Psychiatry 2003; 182: 63-7.

37 Cookson H, Granell R, Joinson C, Ben-Shlomo Y, Henderson AJ. Mothers' anxiety during pregnancy is associated with asthma in their children. $J$ Allergy Clin Immunol 2009: 123: 847-853.e11.

38 Giallo R, Bahreinian S, Brown S, Cooklin A, Kingston D, Kozyrskyj A. Maternal depressive symptoms across early childhood and asthma in school children: findings from a longitudinal Australian population based study. PLOS One 2015: 10(3): e0121459.

39 Lange NE, Bunyavanich S, Silberg JL, Canino G, Rosner BA, Celedón JC. Parental psychosocial stress and asthma morbidity in Puerto Rican twins. J Allergy Clin Immunol 2011; 127: 734-40.

40 Brew BK, Lundholm C, Viktorin A, Lichtenstein P, Larsson $\mathrm{H}$, Almqvist C. Longitudinal depression or anxiety in mothers and offspring asthma: a Swedish population-based study. Int J Epidemiol 2018; 47: 166-74.

41 Magnus MC, Wright RJ, Røysamb E, Parr C, Karlstad Ø, Page C, et al. Association of maternal psychosocial stress with increased risk of asthma development in offspring Am J Epidemiol 2018; 187: 1199-209. 
42 Klinnert MD, Nelson HS, Price MR, Adinoff AD, Leung DYM, Mrazek DA. Onset and persistence of childhood asthma: predictors from infancy. Pediatrics 2001; 108: e69.

43 Kozyrskyj AL, Letourneau NL, Kang LJ, Salmani M. Associations between postpartum depressive symptoms and childhood asthma diminish with child age. Clin Exp Allergy 2017; 47: 324-30.

44 Kozyrskyj AL, Mai X-M, McGrath P, HayGlass KT, Becker AB, MacNeil B. Continued exposure to maternal distress in early life is associated with an increased risk of childhood asthma. Am J Respir Crit Care Med 2008; 177: 142-7.

45 Wang IJ, Wen HJ, Chiang TL, Lin SJ, Guo YL. Maternal psychologic problems increased the risk of childhood atopic dermatitis. Pediatr Allergy Immunol 2016; 27: 169-76.

46 Letourneau NL, Kozyrskyj AL, Cosic N, Ntanda HN, Anis L, Hart MJ, et al. Maternal sensitivity and social support protect against childhood atopic dermatitis. Allergy Asthma Clin Immunol 2017; 13: 26.

47 Elbert NJ, Duijts L, den Dekker HT, de Jong NW, Nijsten TE, Jaddoe VW, et al. Maternal psychiatric symptoms during pregnancy and risk of childhood atopic diseases. Clin Exp Allergy 2017; 47: 509-19.

48 De Sousa A. Maternal, child and family factors in childhood obesity. Int Diabetes Metab 2009; 17: 111-2.

49 Bronte-Tinkew J, Zaslow M, Capps R, Horowitz A, McNamara M. Food insecurity works through depression, parenting, and infant feeding to influence overweight and health in toddlers. J Nutr 2007; 137: 2160-5.

50 Ajslev TA, Andersen CS, Ingstrup KG, Nohr EA, Sørensen TIA. Maternal postpartum distress and childhood overweight. PLOS One 2010; 5(6): e11136.

51 Santos IS, Matijasevich A, Domingues MR, Barros AJD, Barros FCF. Long-lasting maternal depression and child growth at 4 years of age: a cohort study. $J$ Pediatr 2010; 157: 401-6.

52 Guxens $M$, Tiemeier $H$, Jansen PW, Raat $H$, Hofman A, Sunyer J, et al. Parental psychological distress during pregnancy and early growth in preschool children: The generation R study. Am J Epidemiol 2013; 177: 538-47.

53 Wang L, Anderson JL, Dalton III WT, Wu T, Liu X, Zheng S, et al. Maternal depressive symptoms and the risk of overweight in their children. Matern Child Health J 2013; 17: 940-8

54 Audelo J, Kogut K, Harley KG, Rosas LG, Stein L, Eskenazi B. Maternal depression and childhood overweight in the CHAMACOS study of Mexican-American children. Matern Child Health J 2016; 20: 1405-14.

55 Blanco M, Sepulveda AR, Lacruz T, Parks M, Real B, Martin-Peinador Y, et al. Examining maternal psychopathology, family functioning and coping skills in childhood obesity: a case-control study. Eur Eat Disord Rev 2017; 25: 359-65.

56 Wojcicki JM, Holbrook K, Lustig RH, Epel E, Caughey AB, Muñoz RF, et al. Chronic maternal depression is associated with reduced weight gain in Latino infants from birth to 2 years of age. PLOS One 2011; 6(2): e16737.

57 Figueiredo RdO, Roos E, Eriksson JG, Simola-Ström S, Weiderpass E. Maternal alcohol and tobacco consumption and the association with their 9 to 14-yearold children's body mass index. Scand J Public Health 2017; 45: 503-10.

58 de Miranda CT, Turecki G, de Jesus Mari J, Andreoli SB, Marcolim MA, Goinman S, et al. Mental health of the mothers of malnourished children. Int J Epidemiol 1996; 25: 128-33.

59 Anoop S. Maternal depression and low maternal intelligence as risk factors for malnutrition in children: a community based case-control study from South India. Arch Dis Child 2004; 89: 325-9.

60 Adewuya AO, Ola BO, Aloba OO, Mapayi BM, Okeniyi JAO. Impact of postnata depression on infants' growth in Nigeria. J Affect Disord 2008; 108: 191-3.

61 Santos DS, Santos DN, De Cássia Ribeiro Silva R, Hasselmann MH, Barreto ML. Maternal common mental disorders and malnutrition in children: a case-control study. Soc Psychiatry Psychiatr Epidemiol 2011; 46: 543-8.

62 Ashaba S, Rukundo GZ, Beinempaka F, Ntaro M, LeBlanc JC. Maternal depression and malnutrition in children in southwest Uganda: a case control study. BMC Public Health 2015; 15: 1303.

63 Rahman A, Iqbal Z, Bunn J, Lovel H, Harrington R. Impact of maternal depression on infant nutritional status and illness. Arch Gen Psychiatry 2004; 61: 946-52.

64 Okronipa H, Marquis G, Lartey A, Brakohiapa L, Perez-Escamilla R, Mazur RE. Postnatal depression symptoms are associated with increased diarrhea among infants of HIV-positive Ghanaian mothers. AIDS Behav 2012; 16: 2216-25.

65 Weobong B, ten Asbroek AHA, Soremekun S, Gram L, Amenga-Etego S, Danso S, et al. Association between probable postnatal depression and increased infant mortality and morbidity: findings from the DON populationbased cohort study in rural Ghana. BMJ Open 2015; 5(8): e006509.
66 Ban L, Gibson JE, West J, Tata LJ. Association between perinatal depression in mothers and the risk of childhood infections in offspring: a population-based cohort study. BMC Public Health 2010; 10: 799.

67 Sarkola T, Gissler M, Kahila H, Autti-Rämö I, Halmesmäki E. Early healthcare utilization and welfare interventions among children of mothers with alcohol and substance abuse: a retrospective cohort study. Acta Paediatr 2011; 100: 1379-85.

68 Phelan KJ, Morrongiello BA, Khoury JC, XU Y, Liddy S, Lanphear B. Maternal supervision of children during their first 3 years of life: the influence of maternal depression and child gender. J Pediatr Psychol 2014; 39: 349-57.

69 Cleaver H, Nicholson D, Tarr S, Cleaver D. Child Protection, Domestic Violence and Parental Substance Misuse: Family Experiences and Effective Practice. Jessica Kingsley, 2007.

70 Chen $\mathrm{YH}$, Lee $\mathrm{HC}$, Lin HC. Prevalence and risk of atopic disorders among schizophrenia patients: a nationwide population based study. Schizophr Res 2009; 108: 191-6.

71 Pedersen MS, Benros ME, Agerbo E, Børglum AD, Mortensen PB. Schizophrenia in patients with atopic disorders with particular emphasis on asthma: a Danish population-based study. Schizophr Res 2012; 138: 58-62.

72 Fitzsimons E, Goodman A, Kelly E, Smith JP. Poverty dynamics and parental mental health: determinants of childhood mental health in the UK. Soc Sci Med 2017; 175: 43-51.

73 Wickham S, Whitehead M, Taylor-Robinson D, Barr B. The effect of a transition into poverty on child and maternal mental health: a longitudinal analysis of the UK Millennium Cohort Study. Lancet Public Heal 2017; 2: e141-8.

74 Björkenstam C, Kosidou K, Björkenstam E. Childhood adversity and risk of suicide: cohort study of 548721 adolescents and young adults in Sweden. BMJ 2017; 357: j1334.

75 Fagundes $C P$, Kiecolt-glaser JK. Stressful early life experiences and immune dysregulation. Brain Behav Immun 2014; 27: 8-12

76 Sternthal MJ, Enlow MB, Cohen S, Canner MJ, Staudenmayer J, Tsang K, et al. Maternal interpersonal trauma and cord blood IgE levels in an inner-city cohort: a life-course perspective. J Allergy Clin Immunol 2009; 124: 954-60.

77 Fisher J, Cabral de Mello M, Patel V, Rahman A, Tran T, Holton S, et al. Prevalence and determinants of common perinatal mental disorders in women in low- and lower-middle-income countries: a systematic review. Bull World Health Organ 2012; 90: 139-149G.

78 Gavin NI, Gaynes B, Lohr KN, Meltzer-Brody S, Gartlehner G, Swinson T. Perinatal depression: a systematic review of prevalence and incidence. Obstet Gynecol 2005; 106: 1071-83.

79 Gelaye B, Rondon M, Araya R, Williams MA. Epidemiology of maternal depression, risk factors, and child outcomes in low-income and middleincome countries. Lancet Psychiatry 2016; 3: 973-82.

80 Surkan PJ, Kennedy CE, Hurley KM, Black MM. Maternal depression and early childhood growth in developing countries: systematic review and meta-analysis. Bull World Health Organ 2011; 89: 608-15.

81 Walker SP, Wachs TD, Meeks Gardner J, Lozoff B, Wasserman GA, PollittE, et al. Child development: risk factors for adverse outcomes in developing countries. Lancet 2007; 369: 145-57.

82 Elliott I. Poverty and Mental Health: A Review to Inform the Joseph Rowntree Foundation's Anti-Poverty Strategy. Mental Health Foundation, 2016.

83 Bradley RH, Corwyn RF. Socioeconomic status and child development. Annu Rev Psychol 2002; 53: 371-99.

84 Lewis AJ, Austin E, Galbally M. Prenatal maternal mental health and fetal growth restriction: a systematic review. J Dev Orig Health Dis 2016; 7: 416-28.

85 King-Hele S, Webb RT, Mortensen PB, Appleby L, Pickles A, Abel KM. Risk of stillbirth and neonatal death linked with maternal mental illness: a national cohort study. Obstet Gynecol Surv 2009; 64: 439-41.

86 Stein A, Pearson RM, Goodman SH, Rapa E, Rahman A, McCallum M, et al. Effects of perinatal mental disorders on the fetus and child. Lancet 2014; 384: 1800-19.

87 Clapton G. Dad Matters: Why Fathers Should Figure in Your Work. Fathers Network Scotland, 2014 (http://www.fathersnetworkscotland.org.uk/archive/ DadMatters.pdf)

88 Lawlor DA, Tilling K, Smith GD. Triangulation in aetiological epidemiology. Int J Epidemiol 2016; 45: 1866-86. 